\title{
Cooperative clinics revolutionizing primary care in Nepal
}

Published at www.cmaj.ca on July 15

$\mathrm{T}$ he women's cooperative clinic in Kathmandu, Nepal, takes up two small rooms in a building on a hill where the city's brightly painted, low-rise apartment buildings end and a rolling, green field of small family plots begins. It features a thin lumpy mattress on an examining bed; a small shelf of antibiotics and a tray with contents that seem to have been transported from the 1930s (a tongue compressor, a mercury thermometer and a leather pouch filled with gauze).

It may be rudimentary, but the cooperative is part of a revolution in primary care in Nepal.

"If I went to the government clinic, I would have to wait five, maybe six hours," says Purna Maharjan, who has come to the clinic because of dizziness and a headache.

A farmer, mother and tailor, Maharjan has paid the per-visit fee of 25 rupees (about 35 cents) because she views the care as more comprehensive than that offered at government facilities. "Here, I can ask the doctor how I should take the medicine. At a government clinic, you don't have time to do that."

Indeed, government health care has become renowned for pushing patients out the door, as well as damaged medicines, informal fees and health workers who try to convince patients to visit their private clinics.

The chaotic world of Nepalese health care has spawned an array of care delivery mechanisms, including primary health care cooperatives, which first began surfacing in wealthier communities and neighbourhoods.

They are slowly spreading to poor communities as it becomes apparent that primary care is a major deficiency of the government system, which is perceived as sub-par because of corruption and inadequate funding, says Dr. Tulsi Narayan Shresth, the rotating doctor for six health care cooperatives.

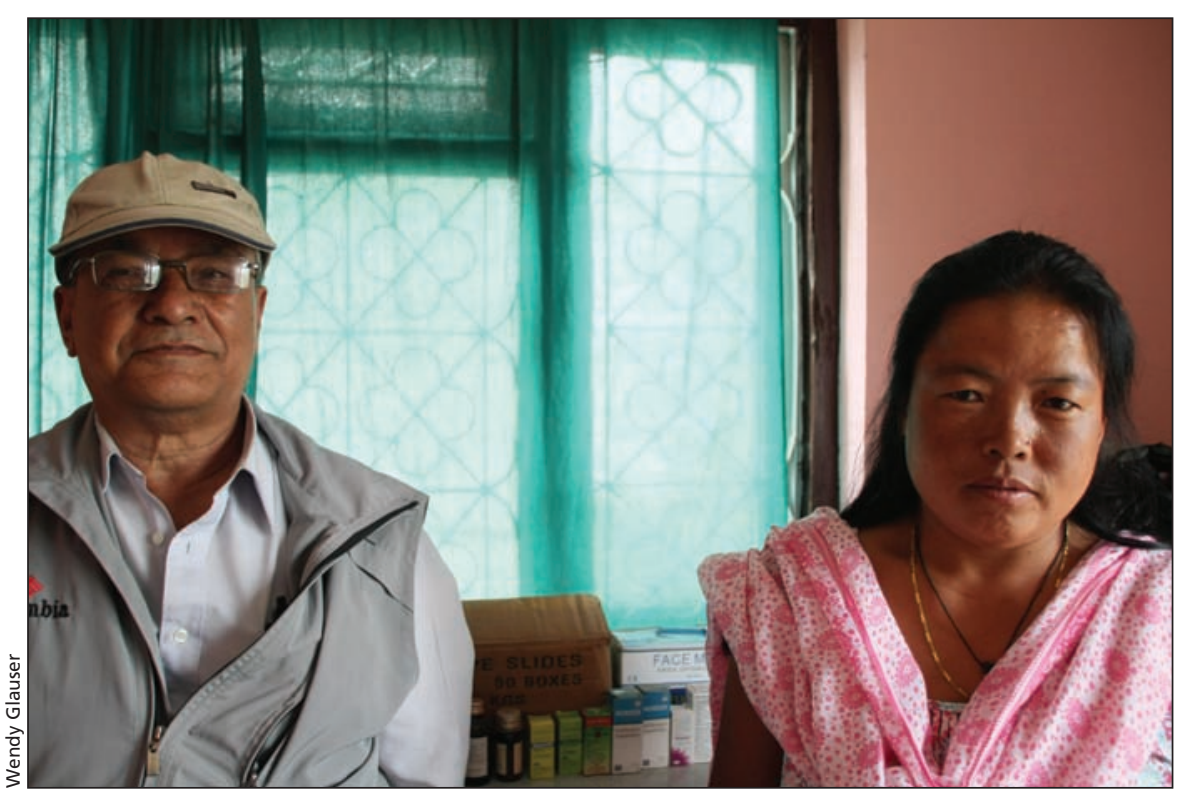

Dr. Tulsi Narayan Shresth and Nirmala Rana, chair of the women's cooperative.

International donors "provide money for polio and other vaccinations, but not for basic health care."

To fill the gap, the nongovernmental organization, Public Health Concern Trust, which is partly financed by the Canadian International Development Agency, has facilitated the development of six cooperatives that serve more than 2500 people. The trust provides the rotating doctor as well as technical support to five of the cooperatives.

The cooperatives offer patients membership at an annual family fee of $\$ 2$ to $\$ 4$ per year, for which they receive clinic services, as well as a $50 \%$ discount on fees at the Kathmandu Model Hospital operated by the trust. (Full hospital subsidies are available for the extremely poor.) Alternatively, patients can cough up the pervisit fee.

While the Public Health Concern Trust provides some technical and part-time staffing support, the bulk of operations are funded through the annual patient fees or special initiatives. The women's health cooperative, for example, receives 15 cents per month from each of roughly $600 \mathrm{sec}-$ ondary school students in exchange for two annual check-ups and free medications, if needed.

While government facilities can be plagued by bureaucracy, community cooperatives can be creative, Shresth says. "This women's cooperative gets a lot of money from the secondary school program. The government can't take these kind of innovative measures."

Governance is typically vested with members who meet monthly, although some cooperatives, like the women's one, are run by representatives of each community they serve. They often run special initiatives. The women's cooperative, for example, has a training program for teachers and students on the prevention of diarrhea, which has been estimated to cause 30000 deaths in Nepal annually ( $J$ Water Health 2004;2:71-81).

Community entrenchment can facilitate more comprehensive and longterm conversations on prevention and health promotion, says Pradhan. "For example, the community may see alco- 
holism as rampant and so they may want to address that. We look at health issues comprehensively."

The cooperatives will often target specific populations, adolescents or aging women, he adds. "We're addressing many of the social taboos. For example, many people say a woman who is pregnant should not take vegetables."
Shresth notes that primary care at clinics is often seasonal. "In the winter, I see a lot of pneumonia and in the summer, it is mainly dysentery and gastric disorders."

Shresth visits each cooperative one to two times per week. On other days, clinics are staffed by a paramedic or a senior auxiliary health worker. On average, about 60 patients visit each cooperative daily. By contrast, a paramedic at a government hospital may see 200 patients each day.

"Sometimes, the government doctors will just look at the patient and write a prescription without even talking to the patient," says Shresth. Wendy Glauser, Kathmandu, Nepal

DOI:10.1503/cmaj.109-3298 